\title{
Types of congenital nonsyndromic ichthyoses
}

\author{
Blanka Pinkovaa , Hana Buckovaa ${ }^{a}$ Romana Borskab ${ }^{b}$ Lenka Fajkusovab
}

Congenital ichthyoses are a very heterogeneous group of diseases manifested by dry, rough and scaling skin. In all forms of ichthyoses, the skin barrier is damaged to a certain degree. Congenital ichthyoses are caused by various gene mutations. Clinical manifestations of the individual types vary as the patient ages. Currently, the diagnosis of congenital ichthyoses is based on molecular analysis, which also allows a complete genetic counseling and genetic prevention. It is appropriate to refer the patients to specialized medical centers, where the cooperation of a neonatologist, a pediatric dermatologist, a geneticist and other specialists is ensured.

Key words: ichthyosis, diagnostics, molecular analysis of DNA, therapy

Received: July 6, 2020; Revised: October 8, 2020; Accepted: October 12, 2020; Available online: October 21, 2020 https://doi.org/10.5507/bp.2020.050

(c) 2020 The Authors; https://creativecommons.org/licenses/by/4.0/

${ }^{a}$ Children's Dermatological Department of the Paediatric Clinic, Faculty of Medicine, Masaryk University and University Hospital Brno, Czech Republic

${ }^{b}$ Center of Molecular Biology and Gene Therapy IHOK University Hospital Brno and Faculty of Medicine, Masaryk University, Brno, Czech Republic

Corresponding author: Blanka Pinkova, e-mail: b.pinkova@seznam.cz

\section{INTRODUCTION}

Ichthyoses are a very heterogeneous group of more than 20 diseases manifested by very dry, rough and scaling skin. They belong into a group of rare diseases - keratodermies. The extent and severity of the disease varies significantly from symptoms such as soft, peeling skin up to extensive generalized involvement, sometimes involving other organs apart from the skin as well ${ }^{1,2}$.

The heredity is generally autosomal dominant or $\mathrm{X}$-linked recessive, but the autosomal recessive (AR) heredity $^{3}$ predominates in rarer types.

\section{ETIOLOGY}

The ichthyoses are caused by various disorders in terminal differentiation of epidermis. These include defects of structural proteins of cytoskeleton - i.e. keratin, nonadhesive and transmembrane proteins such as for example konexins or "cornified envelope" proteins such as filaggrin or loricrin 4 . The "cornified envelope" (CE) is a layer of protein about 10-20 nm thick, which provides a vital barrier for the organism. Its extraordinary impermeability is largely caused by the interconnection of proteins networked using transglutaminase-1 (TGM 1) (ref. ${ }^{5}$ ).

In all congenital forms of ichthyosis, the skin barrier is damaged to a certain degree, causing higher transepidermal water loss (TEWL) and decrease in the ability to retain sufficient amount of water in epidermis ${ }^{6}$.

The increased transepidermal water loss (TEWL) is a signal starting the restoration of the main barrier components, telling them to initiate production of keratinocytes or intercellular matter. The intercellular matter is produced by Odland bodies. These bodies are located in a more superficial layer of stratum spinosum and they expel their content into intercellular spaces via the cell membrane. This matter is turned into an impermeable matter with lipid content (from Odland bodies) and it forms a putty-like substance of stratum corneum.

In case of diseases with persisting barrier defect, regenerative processes continue and they lead to epidermal hyperplasia, hyperkeratosis and frequently also erythema. Hyperproliferation is considered a compensation mechanism, which leads to a restoration of this barrier ${ }^{7}$.

The abnormalities in desquamation result in an accumulation of corneocytes (retention hyperkeratosis) or in an increased proliferation (epidermal hyperplasia) (ref. ${ }^{8}$ ).

\section{DIAGNOSTICS}

The classification of congenital ichthyosis originates in clinical picture, histological diagnosis, histochemical results and molecular diagnostics. Clinical manifestations of the individual types of ichthyoses vary widely. The manifestations change as patient ages and they also change on the basis of season of the year. Some congenital ichthyoses manifest themselves already in newborns, in case of other types, the symptoms appear later. However, classification of the type of ichthyosis in accordance with the clinical picture and histological examination currently does not suffice even to experienced dermatologists. This is why diagnostics on the molecular level ${ }^{9}$ make the largest contribution to correct determination of ichthyosis type.

\section{Histological screening}

Common histopatological changes are not in any way limited to ichthyoses, we often only find epidermal hyperplasia and various degrees of orthohyperkeratosis. 
Electron microscopy plays an important role in the diagnostics of ichthyoses and their ultrastructural markers. In the individual types of ichthyoses, we discover changes in the amount of lamellar bodies or changes in stratum corneum. The density of lamellar bodies is decreased, they are smaller and often manifest a vacuolar shape, and therefore, they do not fully fulfill their role. This very abnormal organization of lamellar bodies leads to a decreased barrier function of the skin.

\section{Molecular diagnostics}

Molecular genetic methods currently play an irreplaceable role in diagnoses of ichthyoses. With the molecular analysis of DNA, pathogenic mutations can be identified in patients and prognosis of the ichthyosis can be expressed. After the pathogenic mutations are identified in a patient, molecular analysis of DNA can be offered to determine carriership of these mutations among patient's relatives as well. These examinations are connected to a complex generic counseling led by an experienced clinical geneticist and to an offer of options of genetic prevention in patient's family. The molecular analysis of DNA already replaces the histological examination in most cases.

The main method used in molecular diagnostics is the next-generation sequencing, NGS (ref. ${ }^{10,11}$ ). The NGS started to appear in clinical diagnostics only after 2010. It replaced the, until then, most often used Sanger method, which has also been called a first generation method. The fact that just a single molecule can be used as a template is the main advantage over regular sequencing.

\section{THERAPY}

Even though the diagnostic options of ichthyoses have improved significantly in the past decade, in case of congenital ichthyoses, the therapy is only symptomatic and topical therapy predominates. Systemic therapy with retinoids is used as an exception. Causal gene therapy is still in the development phase. More therapeutic options are described with individual types of ichthyoses.

\section{CLASSIFICATION}

The current revised classification written by French authors in 2018 builds on the joint classification of European authors from 2009. It includes division to 4 basic, most frequent types of ichthyoses and less frequent, rarer ichthyoses ${ }^{12,13}$.

\section{ICHTHYOSIS VULGARIS (IV)}

With regard to prevalence of $1: 250$, this is the most frequent type of ichthyosis.

IV is an $\mathrm{AD}$ disease, or semi-dominant, which means that in case of affliction of both parents, the clinical condition of the patient is worse than only one of the parents. This disease is based on loss-of function-mutation for fil- aggrin, (FLG: 1q21 chromosome), which belongs to the skin differentiation complex. The filaggrin is the main component of keratohyalin proteins and it participates in interconnection of keratin filaments. The mutations in the gene for filaggrin also increase the risk of atopic dermatitis - in approximately $40 \%$ of cases $^{14,15}$.

Ichthyosis vulgaris can manifest itself in newborns with an increased dryness of the skin and fine white flaking, but the clinical symptoms mostly manifest themselves around the sixth month of age. Predilection locations include extensor sides of limbs - especially shins and also abdomen. Patient's face and flexor sides of limbs tend to be spared. Palm hyperlinearity is found in $80-90 \%$ of patients. Skin dryness is more pronounced in winter ${ }^{16}$.

During histological examination, epidermal hyperplasia and various degrees of orthohyperkeratosis are found; stratum granulosum is narrowed or missing. Diminished keratohyalin granules are visible under electron microscope.

Local therapy is the basis for treatment of ichthyosis vulgaris. We use lighter - hydrophilic bases, so that the occlusive effect of external preparations would not occur. We choose preparations containing glycerol, and in case of larger scaling, we even use preparations with of $5 \%$ concentration of urea, except for infants. Systemic therapy with retinoids is not indicated on ichthyosis vulgaris. With regard to the mild manifestations, the disease prognosis is very good.

\section{X-LINKED RECESSIVE ICHTHYOSIS (XLI)}

With the incidence rate of 1: 2000 to 1: 6000 boys, XLI represents the second most frequent type of ichthyosis. It only affects boys, women are carriers.

XLI develops on the basis of a defect of a steroid sulfatase enzyme (STS) the gene for this enzyme is coded on Xp 22.32 chromosome.

XLI sometimes manifests itself right after childbirth; very rarely are children born as collodion babies. More frequently, it will manifest itself in the first two or three months of a child's life, and it starts with predominating generalized flaking of small whitish scales, which usually do not form in cubital and popliteal fossae. At the age of four to six months, the scales are polygonal, rougher and grey-brown. The scales are affixed to the underlying surface with their centers, and at later age, they appear especially in the area of nape of the neck and in retroauricular areas, but also on extensor sides of limbs and body sides. Flexor sides are usually spared. Sometimes the disease involves face, or rather its preauricular part, and also the hairy part of the head, where we can find a coat of firmly affixed scales. The patients do not suffer from palm hyperlinearity and don't have manifestations of atopic dermatitis. The condition of skin-related manifestations typically improves in the summer. The severity of manifestations also decreases with age.

In $50 \%$ of boys suffering from this disease and $25 \%$ of female carriers, this disease is associated with cornea thickening as a result of accumulation of cholesterol sul- 
fate on the rear membrane, however mostly without any functional consequences. Gonadal dysfunctions (cryptorchidism and infertility) have been recorded in $24 \%$ of patients. As regards to mothers of boys suffering from XLI, typical problems include weak labor pains, protracted labor, which often becomes an indication for a Cesarean section $^{17}$.

There are no typical histological changes associated with XLI, we only register minor hyperkeratosis with acanthosis and preserved str. granulosum.

In patients suffering from XLI, we can only choose from local therapy, hydrophilic preparations, in case of hyperkeratosis on nape of the neck, we use preparations containing urea; on smaller regions, you can use concentration of up to $10 \%$, but in general use, only up to $5 \%$.

\section{AUTOSOMAL RECESSIVE CONGENITAL ICHTHYOSIS (ARCI)}

This section covers the entire spectrum of autosomal recessive congenital ichthyoses. That is why their acronym is ARCI (autosomal recessive congenital ichthyoses). The incidence rate is estimated between 1:100,000 to $1: 300,000$ (ref. $^{18}$ ).

The etiology is very heterogeneous; using molecular genetics, more than 7 gene mutations can be differentiated.
The most frequent are mutations in $A L O X E 3$ and $A L O X$ $12 B$ genes, see Table 1 (ref. ${ }^{19}$ ). These are lipoxygenases, enzymes that break down arachidonic acid derivatives leukotrienes into other metabolites ${ }^{20}$. Mutations of these genes lead to a significantly damaged barrier function of the skin and therefore to water losses through skin. The second most frequently mutating gene is the gene for transglutaminase-1 ( $T G M$ 1), an enzyme necessary for creation of "cornified envelope". Transglutaminase-1 is responsible for creation of "cross-linked" corneocytes, it helps keeping them together and decrease epidermal water losses in that way ${ }^{21,22}$.

ARCI can be divided into 2 basic groups: lamellar ichthyosis (LI) and congenital ichthyosiform erythroderma (CIE). Apart from these 2 basic types, we can also classify other, less frequent types of ichthyoses into this group, see Table 1.

Independently on the different etiology, children suffering from ARCI manifest several common clinical symptoms $^{23,24}$ :

Collodion baby (CB): in $80-90 \%$ of patients suffering from LI and CIE, the surface of a newborn's body is covered with a colloidal membrane, which can be compared to a thick cellophane. This is not a specific manifestation of a specific type of ichthyosis. Newborns have bright red, shiny, stiff parchment-like skin. Rarely, a localized membrane can appear only on a certain part of the body ${ }^{25}$.

Table 1. Comparison of the most common types of ichthyosis. (ref.64 )

\begin{tabular}{|c|c|c|c|c|c|}
\hline & Ichthyosis vulgaris & $\begin{array}{l}\text { X-linked recessive } \\
\text { ichthyosis }\end{array}$ & $\begin{array}{l}\text { Keratinopathic } \\
\text { ichthyosis }\end{array}$ & $\begin{array}{l}\text { ARCI: Classic } \\
\text { lamellar ichthyosis }\end{array}$ & $\begin{array}{l}\text { ARCI: Classic } \\
\text { congenital } \\
\text { ichthyosiform } \\
\text { erytroderma }\end{array}$ \\
\hline $\begin{array}{l}\text { Incidence } \\
\text { rate }\end{array}$ & $1: 250$ & $1: 2,000-6,000$ males & $1: 300,000$ & $1: 300,000$ & $1: 300,000$ \\
\hline Inheritance & $\begin{array}{l}\text { Autosomal } \\
\text { semi-dominant }\end{array}$ & X-linked recessive & $\begin{array}{l}\text { Usually autosomal } \\
\text { dominant }\end{array}$ & Autosomal recessive & Autosomal recessive \\
\hline Onset & $\begin{array}{l}2 \text { months and } \\
\text { beyond }\end{array}$ & $\begin{array}{l}17 \% \text { at birth; } 83 \text { by } \\
1 \text { st year }\end{array}$ & $\begin{array}{l}\text { Birth, with } \\
\text { superficial blistering }\end{array}$ & $\begin{array}{l}\text { Birth, as a collodion } \\
\text { baby }\end{array}$ & $\begin{array}{l}\text { Birth, as a collodion } \\
\text { baby }\end{array}$ \\
\hline $\begin{array}{l}\text { Character of } \\
\text { scales }\end{array}$ & $\begin{array}{l}\text { Fine white to larger } \\
\text { scales, esp. on legs }\end{array}$ & Large, brown & $\begin{array}{l}\text { Verrucous scale, } \\
\text { superficial blisters }\end{array}$ & $\begin{array}{l}\text { Large, platelike } \\
\text { scales }\end{array}$ & $\begin{array}{l}\text { Fine white scaling } \\
\text { overlying erythema }\end{array}$ \\
\hline Localization & $\begin{array}{l}\text { Can be generalized, } \\
\text { relative sparing of } \\
\text { flexures, hyperlinear } \\
\text { palms }\end{array}$ & $\begin{array}{l}\text { Accentuation at neck } \\
\text { and behind ears, } \\
\text { relatively sparing } \\
\text { flexures }\end{array}$ & $\begin{array}{l}\text { Generalized, esp. } \\
\text { at flexures and } \\
\text { overlying joints }\end{array}$ & $\begin{array}{l}\text { Generalized, } \\
\text { ectropion, occ. } \\
\text { alopecia, nail } \\
\text { dystrophy }\end{array}$ & $\begin{array}{l}\text { Generalized, } \\
\text { ectropion, occ. } \\
\text { alopecia }\end{array}$ \\
\hline $\begin{array}{l}\text { Distinct } \\
\text { histological } \\
\text { features }\end{array}$ & $\begin{array}{l}\text { Often shows } \\
\text { decreased granular } \\
\text { layer }\end{array}$ & None & $\begin{array}{l}\text { Epidermolytic } \\
\text { hyperkeratosis }\end{array}$ & $\begin{array}{l}\text { Massive } \\
\text { orthohyperkeratosis, } \\
\text { moderate acanthosis }\end{array}$ & More acanthosis \\
\hline $\begin{array}{l}\text { Molecular } \\
\text { basis }\end{array}$ & $\begin{array}{l}\text { Mutations in } \\
\text { profilaggin (FLG), } \\
\text { worse in both alleles }\end{array}$ & $\begin{array}{l}\text { Deletions } \\
\text { in ARSC } 1 \\
\text { (arylsulfatase C) }\end{array}$ & $\begin{array}{l}\text { Mutations in KRT } 1 \\
\text { and } 10 \text {, superficial } \\
\text { form with mutations } \\
\text { in KRT } 2\end{array}$ & $\begin{array}{l}\text { Mutations in TGM } \\
\text { 1, NIPAL 4, ALOX } \\
\text { 12, ABCA } 12 \text { - other } \\
\text { loci }\end{array}$ & $\begin{array}{l}\text { Mutations in } \\
\text { ALOX12, ALOXE3, } \\
\text { NIPAL 4, TGM } 1 \\
\text { other loci, CYP4F22 }\end{array}$ \\
\hline Comments & $\begin{array}{l}\text { Increased risk of } \\
\text { atopic dermatitis and } \\
\text { keratosis pillaris }\end{array}$ & $\begin{array}{l}\text { Accumulation of } \\
\text { cholesterol sulfate, } \\
\text { FISH analysis to } \\
\text { detect deletion, } \\
\text { genital abnormalities } \\
\text { rare, asymptomatic } \\
\text { corneal opacities }\end{array}$ & $\begin{array}{l}\text { Superficial } \\
\text { form shows } \\
\text { more superficial } \\
\text { blistering and much } \\
\text { less thickening, } \\
\text { secondary St.aureus } \\
\text { infection }\end{array}$ & $\begin{array}{l}\text { Transglutaminase } \\
\text { activity can be } \\
\text { measured in skin } \\
\text { samples }\end{array}$ & $\begin{array}{l}\text { May be associated } \\
\text { with neurologic } \\
\text { abnormalities }\end{array}$ \\
\hline
\end{tabular}


The thin, shiny skin can distort both face and limbs. That will manifest itself by ectropions, eclabia, pseudocontractures, absence of eyebrows, sparse hair or a hypoplasia of nasal and auricular cartilage. Rarely, the symptoms include limb ischemia as a result of mechanical compression of limbs with a stiff membrane. The membrane fully avoids the navel and mucous membranes and it ends directly on the boundaries of natural orifices. Hairs usually penetrate the colloidal membrane and only rarely are they covered by this membrane. Nails are usually uninvolved and not covered with this membrane. The membrane will usually peel during the first four weeks, but in some cases, it can persist up to three months of age of the child. CB usually occurs in newborns carried to term but with lower birth weight $(2,500-3,000 \mathrm{~g})$ or in children born before term.

In 5-6\% of newborns, the collodion baby will not develop into any form of ichthyosis, this is a "Self Improving Congenital Ichthyosis" (SICI) $\left(\right.$ ref. $^{26}$ ).

The damaged epidermal barrier represents a high risk in CB. Typically, TEWL (transepidermal water loss) is increased, in some cases up to seven times larger in comparison to a full-term newborn. Byuse et al. have discovered that in CB, TEWL is initially very high and gradually improves as the membrane detaches.

Placing the newborn into an incubator soon after labor also prevents or at least decreases the hypernatremic dehydration and hyponatremia as a result of excessive TEWL. The excessive water loss through skin is associated with heat loss, impaired thermoregulation and hypernatremic dehydration. CB is often associated with hypohidrosis. The impaired skin barrier increases the probability of both bacterial and yeast infection. Candida albicans, which thrives in the wet environment of the incubator, is a frequent pathogen. That is why a newborn's stay in the incubator is limited to the shortest possible time, so that the infectious complications were prevented. Pneumonia caused by aspiration of scales from the amniotic fluid can be a more serious infectious complication ${ }^{27,28}$.

With regard to the constantly improving neonatal care, the mortality rate of children with $\mathrm{CB}$ has a decreasing tendency. The mortality rate gradually decreases from $50 \%$ in 1966 over $11 \%$ in 1986 to the current $5 \%$. A child stays in the incubator with elevated humidity (70-80\%) for approximately 2 weeks, but the humidity is gradually decreased because of the risk of associated skin infections and the child is soon transferred to a bed ${ }^{29-31}$.

The skin is treated with hydrophilic creams, rhagades are lined with disinfectant solutions and treated with external preparations, which support epithelization, and combined with zinc preparations. External auditory canal is softened with external hydrophilic preparations or paraffin oil and eyes are treated regularly to prevent cornea damage $^{32,33}$.

Other common symptoms of ARCI include palmoplantar hyperkeratosis, sometimes transformations of nails, alopecia and, last but not least, hypohidrosis.

\section{a) Lamellar ichthyosis (LI)}

Lamellar ichthyosis forms the first large group of ARCI. The incidence rate is around 1: 300,000. The congenital type is $\mathrm{AR}$, but also $\mathrm{AD}$ in some cases.

The individual subtypes of LI have a different genotype, but similar phenotype. The most frequent mutations are:

TGM 1 in 32\%, NIPAL 4 (ichthyin) in 16\%, ALOX $12 B$ in $12 \%, C Y P 4 F 22$ in $8 \%, A L O X E 3$ in $5 \%$, and in $22 \%$, no mutation has been proven so far (ref. $\left.{ }^{34-36}\right)$.

The skin manifestations of LI are very varied. $80-90 \%$ of babies are born as collodion babies. After peeling of the membrane, the skin is less reddened in comparison to CIE and it manifests larger, rougher scales. Other manifestations include skin ragades, ectropions, eclabia and nail deformities. Approximately $70 \%$ of patients suffer from palmoplantar hyperkeratosis. As a consequence of this skin disease, at early age, growth curve can be delayed in children suffering from LI, but the curve eventually evens out. However, there is no mental retardation ${ }^{37,38}$.

\section{b) Congenital ichthyosiform erythroderma (CIE)}

CIE is the second large subgroup of ARCI. This disease has mostly autosomal recessive heredity. Similarly to LI, the molecular genetic examination overlaps in case of CIE and it manifests gene mutations for the same enzymes, see Table 1 . In case of CIE, gene mutations for ALOXE3 and ALOX12B predominate slightly ${ }^{39,40}$.

The clinical picture of CIE is clinically and genetically heterogeneous. $80-90 \%$ of babies are born as collodion babies. Erythroderma with generalized scaling, which is whitish from the onset and rather soft, is the main symptom. As the disease progresses, the scales roughen and darken. The expression of erythroderma and ectropions varies. Accompanying symptoms often include palmoplantar hyperkeratosis, the extent of which also differs in individual patients. In some children, scarring alopecia and eventually also nail growth disorders can develop. As regards the intellect, the children develop completely regularly ${ }^{41,42}$.

\section{ARCI therapy}

The manifestations of these forms of ichthyoses belong among the more serious and that is why the care incorporates multiple fields. Proper skin care, which is selected in accordance with the degree of severity of clinical manifestations of LI or CIE, is very important. Necessary measures include regular examinations of laboratory markers (skin smears, ions, CRP and FW), proper nutrition, rehydration (especially at the neonatal age and then in accordance with patient's condition approximately to the patient's three years of age).

Especially in the first 3-4 weeks of life, these children are very susceptible to infections and thermolabile and that is why they require an intensive care. After the labor, it is suitable to provide I.V. access through the umbilical vein. After the labor, the newborns have to be wrapped in an aluminum foil and transported to neonatal intensive care unit. Subsequently, they are placed in an incubator 
with $60-80 \%$ humidity in accordance with the clinical picture, the skin must be treated regularly 6-8 times a day; the rehydration of the newborn must be cared for.

Topical treatment is based on the clinical picture. The more reddened the skin is, the softer and more hydrating ointments must be used. In the first weeks of life, the newborn is placed in an incubator, and that is why hydrophilic bases are used on the skin. The humidity gradually decreases and the newborn is placed in a bed. Apart from hydrophilic bases, cream bases can be used as well. Because of the possible thermoregulation impairment on the basis of hyperkeratosis, the ointment bases are contraindicated. The same rules apply in hot summer weather as well. The ideal frequency of application of hydrophilic bases is 6-8 times a day, in case of more fatty bases, the frequency of 3-4 times/day is recommended ${ }^{43,44}$.

In severe forms of LI and CIE, systemic therapy of retinoids (Oral retinoids and retinoic acid metabolism blocking agents (RAMBAs)) can be implemented. The retinoids have keratolytic effect and the function of the orneal layer improves. Both types of retinoids can be used, isotretinoin as well as acitretin. Under exceptional conditions, retinoids can be used on newborns or infants. We have more experience with systemic treatment with school age patients, the retinoid dose is $0.3-0.7 \mathrm{mg} / \mathrm{kg} /$ day. It is taken perorally, but it has a whole range of adverse effects ${ }^{45,46}$. Retinoids significantly improve the diagnosis of hyperkeratosis and ectropions, but not erythroderma. However, the side effects of the therapy are reversible. Before the therapy is initiated, the following examinations have to be performed. X-ray of long bones and spine, complete blood count, liver tests, TAG and cholesterol, urea, creatinine, ions and urine. During the course of the therapy, at first, the examinations above should be performed every 4 weeks in the first two months of the therapy and then every three months. The adverse effects may include: dryness of skin and mucous membranes, whitlows, pyogenic granuloma, skeletal hyperostosis and ligament calcification, which can however be present in other youths as well, and that is why the X-ray also has to be performed before the therapy is initiated. Preliminary closure of epiphyseal splits manifests very rarely in case of very high doses of retinoids. We discover hypertriacylglycerolemia in approximately $25 \%$ of patients and transaminase elevation in approximately $15 \%$ of patients. However, these values depend on the dose and they are reversible ${ }^{47}$.

In patients suffering from ARCI, the following histological changes have been observed: abnormal spacing and interruption of lamellar junctions and intracellular lipid droplets, both withing corneocytes and stratum granulosum cells. Significant orthohyperkeratosis is also being recorded.

\section{c) Harlequin ichthyosis (HI)}

This is a very serious, escalated form of lamellar ichthyosis.

It develops on the basis of a recessively acquired gene mutation for the enzyme $A B C A 12$ /ATP-binding cassette transporter $12 /$. This enzyme is important for lipid transportation and it is coded on the $2 \mathrm{q} 34$ chromosome. As a result of this mutation, the transportation of the newly synthesized glucosylceramide is impaired; instead of into lamellar bodies, it is transported into interstitial spaces of stratum corneum, which leads to a significant decrease of the barrier function of the $\operatorname{skin}^{48}$.

The children are mostly born prematurely with a skin similar to the costume of the Harlequin from the "Commedia dell'arte". The scales are large, strong and with frequent deep ragades. Eclabium and ectropion are strongly manifested, ear lobes are attached to the head, lips form the shape of "O" and appear similar to a fish mouth. With regard to the skin condition, bending contractures develop and fingers and toes are indistinguishable under the coat of scales. With regard to the accumulation of almost plate-like scales, mobility of the entire body is limited ${ }^{49}$.

However, the disease is not associated with other internal or neurological diseases. In comparison to the previously stated data, the later life of the child is relatively normal and the neonatal mortality has even dropped from the previous value of almost $100 \%$ to the current $10 \%$. With regard to the premature birth and the skin condition, the children are mostly endangered by development of infections, further by hyperthermia and by secondary disorders of electrolyte balance ${ }^{50}$. Under intensive therapy, the scales gradually peel after the first few weeks, but over time, they develop in a rather severe form of lamellar ichthyosis.

The therapy is governed by recommendations, which apply to severe types of ichthyoses. The children are placed into an incubator in specialized neonatological facilities, the care is focused on stabilization of body temperature, electrolyte balance and hydration. External preparations with $5-10 \%$ of glycerol are used instead of vaseline bases because of their occlusive character. Further, disinfectant baths are recommended. Epithelization and disinfectant gels or possibly local antibiotics are applied into rhagades.

\section{KERATINOPATHIC ICHTHYOSES}

Epidermolytic ichthyosis, superficial epidermolytic ichthyosis, congenital reticular ichthyosiform erythroderma - ichthyosis with confetti (IWC) and ichthyosis hystrix belong among keratinopathic ichthyoses, formerly referred to as bullous ichthyoses.

This concerns an aggregate group of ichthyoses, which are due to a mutation in a gene for keratin. These genes code keratin, necessary for cell cytoskeleton creation and the normal function and structure of tissues.

These mutations also cause vacuolar degeneration of stratum granulosum and the upper layers of stratum spinosum and therefore lead to a formation of intradermal blisters. At the same time, the process of releasing lipids from lamellar bodies is impaired and these lipids are then not released into intercellular spaces. Epidermolytic hyperkeratosis occurs during childhood. As the gradual thickening of epidermis progresses, formation of blisters decreases ${ }^{51}$. 


\section{a) Epidermolytic ichthyosis (EI) - (formerly bullous congenital ichthyosiform erythroderma BCIE = morbus Brocq)}

This AD congenital disease is based on the mutation of gene for keratin 1 ( $C K 1: 12 q 13)$, possibly keratin 10 (CK 10: chromosome 17q21-22), which leads to characteristic visual symptoms of epidermolytic hyperkeratosis. Patients with the mutation for CK 1 simultaneously suffer from palmoplantar hyperkeratosis, which corresponds to the distribution of CK1 in the body. The incidence rate is approximately $1: 200,000$ to $1: 300,000$.

Clinically, 6 subtypes of EI can be distinguished. The main distinguishing criterion is the palmoplantar keratosis, which is present in type I-III, or it is not present in type IV-V. ( ref. $^{52}$ )

In case of postzygotic, somatic mutation of $\mathrm{CK} 1$ or CK10 in the early embryogenesis, epidermal nevus, which is placed in Blaschko's lines, is formed. If the somatic mosaicism also affects gonadal cells, EI can occur in the next generation. That is why parents of children suffering from EI should be tested for signs of epidermal nevi and if these tests are positive, histology, which may manifest symptoms of epidermolytic hyperkeratosis, must be performed ${ }^{53}$.

Immediately after labor, erythroderma is present in infants as well as widespread erosions, which may appear similar to epidermolysis bullosa congenita or staphylococcal skin scaled syndrome. During the second or third year of life, formation of blisters alleviates, lamellar hyperkeratoses are gradually formed and later gradually turn brown and crest-like.

Dehydration and bacterial superinfection, which endanger the patients during the entire course of their lives, represent the main complications for newborns and infants. Because of the danger of a massive infection and widespread erosions, these children must be transferred to intensive care units after labor. Staphylococcus aureus is a frequent pathogen, total antibiotic therapy has to be considered in accordance with patient's condition.

In older children, the skin infection is connected to an unpleasant smell, which stigmatizes them and excludes them from the society. That is why regular skin swabs, monitoring of the ALSO values and adhering to the skin disinfection principles is necessary.

In histological examination (using EM - electron microscopy) the envelope is cornified and the distribution of lipids in keranocytes is completely regular in EI. However, changes in keratin fibers occur. These fibers form minor groups in cells, which leads to an abnormal function of the cytoskeleton and lamerllar bodies therefore remain "trapped" in keratinocytes and do not fulfill their normal function.

Because of the tendency to form blisters and the erosion, the keratolytic therapy must be performed very carefully, especially in the first year of life. Preparations with high urea content must not be used. Disinfectant baths are suitable. Baths with an addition of sodium bicarbonate may alleviate the accumulation of hyperkeratoses. However, they can't be used on acutely infected, red- dish areas. The skin is softened with hydrophilic creams, which can be combined with zinc or tanine preparations. Antibiotics are used in case of superinfection; most often penicillin or amoxicillin in accordance with sensitivity of the infection ${ }^{56,57}$.

Systemic therapy with acitretin can be used only in heavier cases and with the dose of $0,3 \mathrm{mg} / \mathrm{kg}$ at maximum.

The $C K 1$ mutation leads primarily to manifestations on palms or soles and that is why the acitrecin therapy is necessary upon much consideration and can on the contrary sometimes lead to worsening of skin symptoms.

Mutations in CK10 lead to manifestations on the whole body and limbs; palms and soles as well as face are unaffected - this reflects distribution of CK10 in body. In this case, the therapy with lower doses of retinoids is possible, but it may not be efficient ${ }^{58}$.

\section{b) Ichthyosis Curth - Macklin - \\ (formerly ichthyosis hystrix)}

A rare form of epidermolytic ichthyosis, characterized by spiky scales or verrucose hyperkeratoses reminiscent of a porcupine.

Mutation in KRT 1 is the genetic basis for this disease, but literary sources also describe mutations in KRT 10 . This always concerns a protein chain defect with a subsequent impairment of function in the V2 domain. The changes are usually localized on the 17th chromosome. Similarly to EI, Ichtyosis Curth is AD congenital.

First manifestations appear already in early childhood and the clinical manifestations including diffuse or striped palmoplantar keratosis with possible subsequent flexural contractures quickly worsen: Especially on hands and feet and above large joints, large brown-yellow scales develop.

Sensineural deafness also sometimes develops as well ${ }^{59}$.

In order to distinguish this form from EI, you can use histological examination (EM), in which bi-nuclear cells are visible in case of $\mathrm{IH}$, while grouping of tonofilaments, typical for epidermolytic ichthyosis, is missing.

Therapy consists in very early total application of retinoids.

\section{c) Superficial epidermolytic ichthyosis (formerly ichthyosis bullosa of Siemens)}

This type of ichthyosis is the mildest of the bullous ichthyoses. It is conditioned by a mutation for $C K 2$. Its clinical picture is very similar to EI, but its manifestations are generally milder and can differ in accordance with the season of the year; the symptoms worsen in the summer. Hyperkeratoses are present only in mild form, palmoplantar keratoses are missing completely.

At labor, manifestations of generalized blisters are visible, but with increasing age, the number of manifestations decreases. At later age, the manifestations almost recede and they are located above joints in the form of hyperkeratotic lichenifications.

A "Mauserung phenomenon" manifests clinically on limbs. It is a feature, which does not occur in other types of ichthyoses and it was first described by Siemens. These 
are maculae of apparently normal skin in the middle of hyperkeratotic areas. In German, "Mauserung” stands for moulting ${ }^{60}$.

In a histological examination, we determine epidermolysis only in the upper layers of epidermis.

\section{d) Congenital reticular ichthyosiform erytroderma - ichthyosis with confetti (IWC)}

Confetti ichthyosis (ichthyosis with confetti IWC) is also known as ichthyosis variegata or congenital reticular ichthyosiform erytroderma. It is an autosomal dominant congenital disease. It manifests itself already in labor by the appearance of ichthyosiform erytroderma, or a collodion baby. Erythrodermic and ichthyotic phenotype remains the entire life, but its severity can fluctuate. It is a very rare disease, its incidence is $<1 / 1000000$, only about 40 cases are described worldwide. In accordance with the current classification, IWC belongs to non-syndrome types of ichthyoses ${ }^{61}$.

Formation of confetti-like spots is the basic symptom of this disease. These are whitish maculae of healthy skin up to the size of $0.5-1 \mathrm{~cm}$, which develop during childhood or in later age. Their number gradually increases with age. Their development is the result of negative mutation in KRT 1 or KRT 10 and the confetti deposits therefore represent healthy, repaired skin as a result of reversion of gene mutations for keratin. They start on the body, where they can achieve a size of up to $4 \mathrm{~cm}$, later, they also spread to the limbs. Due to the merging of these deposits, the surrounding ichthyotic skin can acquire an almost reticular character - hence the former name, congenital reticular ichthyosiform erythroderma.

The histological markers of the confetti deposits correspond to regular skin.

In patients suffering from mutations in $K R T 1$, the confetti appear at a later age, around 20th year of their life. In contrast, in patients with KRT 10, they are already visible in childhood. However, in these patients, the IWC symptoms are generally milder.

The main symptoms of IWC include aural deformities including earlobe hypoplasia, alopecia universalis, congenital ichthyosis, ectropia, sometimes even agenesis of the mamillary glands. Growth retardation predominates especially in childhood.

Patients suffering from IWC also tend to develop nonmelanocytic tumors ${ }^{62}$.

Currently, there is no specific or satisfactory therapy available to counter the IWC. In case of formation of contractures, systemic therapy with retinoids has been indicated, or possibly plastic surgery of ears or ectropia.

\section{CONCLUSION}

Even though the ichthyoses are a very heterogeneous group of diseases with a very varied clinical picture, the methods of molecular biology have significantly improved the diagnostics, enabled complex genetic counselling in families in which the ichthyosis has occurred, as well as genetic prevention.
A severely damaged epidermal barrier creates huge demands on neonatal care, but because improvements in neonatology, the survival rate of newborns has increased significantly.

On the other hand, the options of local and systemic therapy remain very limited. No causal treatment exists currently. It is still being developed. Recent research reveals a similarity between genetic mutations in ichthyoses and psoriasis. For this reason, we hope that in the future, systemic therapy with biologicals, so very efficient in the treatment of psoriasis, will be used in systemic therapy of ichthyoses ${ }^{63}$.

In severe types of ichthyoses, cooperation between multiple fields is necessary, ideally in specialized centers connected to neonatological sites. In Europe, these specialized centers are combined into an international team of experts called the European Reference Network - Skin. The patient organization has been developing successfully for the last ten years. Its goal is to support the patients and their families in all matters related to social, legal and advisory services. In the Czech Republic, this association is called Spolek Ichtyóza. Together with specialists, it participates in efforts to improve the quality of life of patients suffering from ichthyosis.

\section{Search strategy and selection criteria}

Our review was aimed to describe types of congenital nonsyndromic ichthyoses.

Scientific articles from 1994 to 2019 were searched using the PubMed and Google scholar. The search terms used were, "ichthyoses”, "ARCI”, " lamellar ichthyosis", "CIE" and "keratinopathic ichthyosis".

\section{ABBREVIATIONS}

ABCA 12, ATP-binding cassette transporter 12; AD, Autosomal dominant; ALOX 12B, Arachidonate 12-lipoxygenase; ALOXE 3, Epidermis-type lipoxygenase 3; AR, Autosomal recessive; ARCI, Autosomal recessive congenital ichthyoses; CIE, Congenital ichthyosiform erythroderma; CK, Cytokeratin; CYP4F22, Cytochrome P450, family 4, subfamily F, polypeptide 22; EI, Epidermolytic ichthyosis; FLG, Fillagrin; KI, Keratinopathic ichthyosis; LI, Lamellar ichthyosis; NIPAL 4, NIPA-like domain containing 4; STS/ARSC 1, Steroidsulfatase/ arylsulfatase C1; TEWL, Transepidermal water loss; TGM 1, Transglutaminase-1; XLI, X linked recessive ichthyosis.

Author contributions: BP: literature search and manuscript writing; HB, RB, LF: corrections and final approval.

Conflict of interest: none declared.

\section{REFERENCES}

\footnotetext{
1. Akiyama $M$, Shimizu H. An update on molecular aspects of the nonsyndromic ichthyoses. Exp Dermatol 2008,(17):371-82.

2. Oji V, Tadini G, Akiyama M, Blanchet Bardon C, Bodemer C, Bourrat E, Coudiere P, DiGiovanna JJ, Elias P, Fischer J, Fleckman P, Gina M,
} 
Harper J, Hashimoto T, Hausser I, Hennies HC, Hohl D, Hovnanian A, Ishida-Yamamoto A, Jacyk WK, Leachman S, Leigh I, Mazereeuw Hautier J, Milstone L, Morice-Picard F, Paller AS, Richard G, Schmuth M, Shimizu H, Sprecher E, Van Steensel M, Taïeb A, Toro JR, Vabres $P$, Vahlquist $A$, Williams $M$, Traupe $H$. Revised nomenclature and classification of inherited ichthyoses: results of the First Ichthyosis Consensus Conference in Sorèze 2009. J Am Acad Dermatol 2010;63(4):607-41.

3. Oji V, Traupe, H. Ichthyoses: differential diagnosis and molecular genetics. Eur J Dermatol 2006,16:349-59.

4. Elias PM, Williams ML, Crumrine D, Schmuth M. Ichthyoses, clinical, biochemical, pathogenic and diagnostic assessment. Curr Probl Dermatol 2010;39:358-64.

5. Candi E, Schmidt R, Melino G. The cornified envelope: a model of cell death in the skin. Nat Rev Moll Cell Biol 2005;6(4):328-40.

6. Vahlquist A, Fischer J, Torma H. Inherited Nonsyndromic Ichthyoses: An Update on Pathophysiology. Am Clin J Dermatol 2018;19(1):5166.

7. Paige DG, Morse Fisher N, Harper Jl. Quantification of stratum corneum ceramides and lipid envelope ceramides in the hereditary ichthyoses. Br J Dermatol 1994;131(1):23-7. doi: 10.1111/j.13652133.1994.tb08452.x.

8. Di Giovanna JJ, Bale SJ. Clinical heterogenity in epidermolytic hyperkeratosis. AMA Arch Derm 1994;130:1026-35.

9. Metzker ML. Sequencing technologies-the next generation. Nat Rev Genet 2010;11(1):31-46. doi: 10.1038/nrg2626

10. Ansorge WJ. Next-generation DNA sequencing techniques. N Biotechnol 2009;25(4):195-203. doi: 10.1016/j.nbt.2008.12.009

11. Tucker T, Marra M, Friedman J. Massively Parallel Sequencing: The Next Big Thing in Genetic Medicine. Am Hum J Genet 2009;85(2):14254 doi:10.1016/j.ajhg.2009.06.022

12. Mazereeuw Hautier J, Hernández Martín A, O'Toole EA, Bygum A Amaro C, Aldwin M, Audouze A, Bodemer C, Diociaiuti A, Bourrat E. Management of congenital ichthyoses: European guidelines of care, part two. Br J Dermatol 2019;180(3):484-95. doi: 10.1111/ bjd.16882

13. Mazereeuw Hautier J, Hernández Martín A, O'Toole EA, Bygum A Amaro C, Aldwin M, Audouze A, Bodemer C, Diociaiuti A, Bourrat E. Management of congenital ichthyoses: European guidelines of care, part one, Br J Dermatol 2019;180(2):272-81. doi: 10.1111/bjd.17203

14. Krug M, Oji V, Traupe $H$, Berneburg M. Ichthyosen - Teil 1 : Differentialdiagnose Vulgärer Ichthyosen und therapeutische Erwägungen. J Dtsch Dermatol Ges 2009;7:511-20.

15. Weidinger S, O'Sullivan M, Illig T, Barnett H, Depner M, Rodriguez E, Ruether A, Klopp N, Vogelberg C, Weiland SK. Filaggrin mutation, atopic eczema, hay fever and asthma in children. J Investig Allergo Clin Immunol 2009;121:1203-9.

16. Preil ML, Traupe H. Diagnostik und Therapie der Ichthyosen. AWMFLeitlinie, Nr.13/043 (Stand: 09/2008).

17. Fernandes NF, Janinner CK, Schwarzt RA. X-linked ichthyosis: an oc culocutaneous genodermatosis. J Am Acad Dermatol 2010;62:480-5.

18. Vahlquist A, Ganemo A, Virtanen M. Congenital ichthyoses: an overview of current and emerging therapies. Acta Derm Venereo 2008;88:4-14.

19. Krieg $P$, Fürstenberger $G$. The role of lipoxygenases in epidermis Biochem Biophys Acta 2014;1841(3):390-400.

20. Traupe H. Rapid categorization of mild types of autosomal recessive congenital ichthyosis undergoing a phenotypic shift: should it be called "pleomorphic ichthyosis" or "congenital ichthyosis with mild scaling (CIMS)"? Acta Derm Venereol 2010;90(5):450-3. doi 10.2340/00015555-0940

21. Rodríguez-Pazos L, Ginarte M, Fachal L, Toribio J, Carracedo A, Vega A. Analysis of TGM1, ALOX12B, ALOXE3, NIPAL4 and CYP4F22 in autosomal recessive congenital ichthyosis from Galicia (NW Spain): evidence of founder effects. Br J Dermatol 2011;165(4):906-11. doi: 10.1111/j.1365-2133.2011.10454

22. Eckl KM, de Juanes S, Kurtenbach J, Nätebus M, Lugassy J, Oji V, Traupe H, Preil ML, Martínez F, Smolle J, Harel A, Krieg P, Sprecher $\mathrm{E}$, Hennies HC. Molecular analysis of 250 patients with autosoma recessive congenital ichthyosis: evidence for mutation hotspots in ALOXE3 and allelic heterogeneity in ALOX12B. J Invest Dermatol 2009;129(6):1421-8. doi: 10.1038/jid.2008.409

23. Höger H. Kindermatologie- differenzialdiagnostik und Therapie be
Kindern und Jugendlichen, 3. vollständing überarbeitete und erweiterte Auflage 2011, ISBN 978-3-7945-2730-4

24. Eckl KM, Krieg $P$, Küster W, Traupe $H$, André $F$, Wittstruck N, Fürstenberger $\mathrm{G}$, Hennies $\mathrm{HC}$. Mutation spectrum and functional analysis of epidermis-type lipoxygenases in patients with autosomal recessive congenital ichthyosis. Hum Mutat 2005;26(4):351-61.

25. Michelle A, Norton PS. Practical Events in the Management of a Collodion Baby, JAMA Dermatol 2015;151(9):1031-32.

26. Vahlquist A, Bygum E, Ganemo A, Fischer J. Genotypic and Clinical Spectrum of Self-Improving Collodion Ichthyosis: ALOX12B, ALOXE3, and TGM1 Mutations in Scandinavian Patients. J Investig Dermatol Symp Proc 2010;(130)2:438-43.

27. Prado R, Ellis L, Gamble, R. Collodion baby: an update, with focus on practical management. J Am Acad Dermatol 2012;67:1362-74.

28. Van Gysel D, Lijnen RL, Moekti SS, Oranje, AP. Collodion baby: a follow -up study of 17 cases. J Eur Acad Dermatol Venereol 2002;16(5):4725.

29. Gustavo A, Gomez R, Weinstein, M. Development of disease severity score for newborns with collodion membrane. J Am Acad Dermatol 2014;70(3):506-11.

30. Mazereew-Hautier J, Aufenvenne, K, Deraison C, Oji, V. Acral-self healing collodion baby: report of a new clinical phenotype caused bz novl TGM1 mutation. Br J Dermatol 2009;161(2):456-63.

31. Akcakus M, Gunes T, Kurtoglu S, Ozturk, A. Collodion baby associated with asymmetric crying faces: a case report. Pediatr Dermatol 2003;20(2):134-6. doi: 10.1046/j.1525-1470.2003.20208.x

32. Taieb A, Labreze C. Collodion baby: what's new. J Am Acad Dermatol 2002;16(5):436-7. doi: 10.1046/j.1468-3083.2002.00478.x

33. Menke TB, Moschner S, Joachimmeyer E. Congenital ectropion in ichthyosis congenita mitis and gravis. Ophthalmologe 2006;103:41015

34. Hackett BC, Fitzgerald D, Watson RM, Hol FA, Irvine AD. Genotypephenotype correlations with TGM1: clustering of mutations in the bathing suit ichthyosis and self-healing collodion baby variants of lamellar ichthyosis. Br J Dermatol 2010;162(2):448-51. doi: 10.1111/ j.1365-2133.2009.09537

35. Aufenvenne K, Oji V, Walker T, Becker-Pauly C, Hennies HC, Stöcker W, Traupe $\mathrm{H}$. Transglutaminase- 1 and bathing suit ichthyosis: molecular analysis of gene/environment interactions. J Invest Dermatol 2009;129(8):2068-71. doi: 10.1038/jid.2009.18

36. Farasat S, Wei MH, Herman M, Liewehr DJ, Steinberg SM, Bale SJ, Fleckman P, Toro JR. Novel transglutaminase- 1 mutations and genotype-phenotype investigations of 104 patients with autosomal recessive congenital ichthyosis in the USA. J Med Genet 2009;46(2):103-11. doi: 10.1136/jmg.2008.060905

37. Lefèvre $C$, Bouadjar B, Ferrand V, Tadini G, Mégarbané A, Lathrop $M$, Prud'homme JF, Fischer J. Mutations in a new cytochrome $\mathrm{P} 450$ gene in lamellar ichthyosis type 3. Hum Mol Genet 2006;15(5):767-76.

38. Hennies, H, Küster, W, Wiebe, V, Krebsová, A. Genotype/phenotype correlation in autosomal recessive lamellar ichthyosis. J Invest Dermatol 2010;130(2):438-43. doi: 10.1038/jid.2009.346

39. Traupe, $\mathrm{H}$. The Ichthyoses - A Guide to Clinical Diagnosis, Genetic Counseling and Therapy. Springer Verlag, Heidelberg 1989, ISBN 3-540-19222-0

40. Krebsová A, Küster W, Lestringant GG, Schulze B, Hinz B, Frossard PM, Reis A, Hennies HC. Identification, by homozygosity mapping, of a novel locus for autosomal recessive congenital ichthyosis on chromosome $17 p$, and evidence for further genetic heterogeneity. Am J Hum Genet 1998;62(5):1052-61. doi: 10.1086/301818

41. Lugassy J, Hennies HC, Indelman M, Khamaysi Z, Bergman R Sprecher E. Rapid detection of homozygous mutations in congenital recessive ichthyosis. Arch Dermatol Res 2008;300(2):81-5.

42. Lefèvre $C$, Bouadjar B, Karaduman A. Mutations in ichthyin a new gene on chromosome 5 q33 in a new form of autosomal recessive congenital ichthyosis. Hum Mol Genet 2005;13(20):2473-82. doi: 10.1093/hmg/ddh263. PMID 15317751

43. Chiaretti A, Schembri Wismayer D, Tortorolo L. Salicylate intoxication using a skin ointment. Acta Paediatr 1997;86:330-1

44. Yamamura S, Kinoshita Y, Kitamura N Neonatal salicylate poisoning during the treatment of a collodion baby. Clin Pediatr 2002;41:451-2.

45. Lacour, M, Mehta Nikhar, B, Atherton, D, Harper, J. An appraisal of acitretin therapy in children with inherited disorders of keratinization. Br J Dermatol 1996;134:1023-9.

46. Ormerod, AD, Campalani, E, Goodfield, MI. Clinical standards Unit 
British Association of dermatologist guidelines on efficacy and use of acitretin in dermatology. Br J Dermatol 2010;162:952-63.

47. Brecher, AR, Orlow, Sl. Oral retinoid therapy for dermatologic conditions in children and adolescents. J Am Acad Dermatol 2003;49:17182.

48. Rajpopat S, Moss C, Mellerio J. Harlequin ichthyosis: a review of clinical and molecular findings in 45 cases. Arch Dermatol 2011;147:6816.

49. Pinková B, Borská R, Fajkusová L, Dostálková D. Gastroenteritida u pacientky s Harlequin ichtyózou. Pediatr pro praxi 2019;20(4):24850.

50. Harvey HB, Shaw MG, Morrell DS. Perinatal management of harlequin ichthyosis: a case report and literature review. J Perinato 2010;30:66-72.

51. Hotz A. Expanding the Clinical and Genetic Spectrum of KRT1, KRT2 and KRT 10 mutations in Keratinopathic Ichthyosis. Acta Derm Venereol 2016: 96(4):473-8. doi: 10.2340/00015555-2299

52. Liu RH, Becker B, Gunkel J. Rapid improvement in digital ischemia and acral contracture in a collodion baby treated with topical tazarotene. J Drugs Dermatol 2010; 9:713-16.

53. Boesen ML, Bygum A, Hertz JM, Zachariassen G. Newborn with se vere epidermolysis bullosa: to treat or not to treat? BMJ Case Rep 2016; 2016:bcr2016214727. doi: 10.1136/bcr-2016-214727

54. Gonzalez ME. Evaluation and treatment of the newborn with epidermolysis bullosa. Semin Perinatol 2013;37:32-9.

55. Ott H, Guthmann F, Ludwikowski B. Interdisciplinary care of newborns with epidermolysis bullosa and severe congenital ichthyoses. Hautarzt 2015;66:236-44.
56. Haneda T, Imai Y, Uchiyama R. Activation of molecular signatures for antimicrobial and innate defense responses in skin with transglutaminase 1 deficiency. PLoS ONE 2016;11:e0159673.

57. Graber CJ, Shane AL, Weintrub P. Clonality of Staphylococcus aureus colonization over time in attendees of a camp for children with chronic dermatoses. Pediatr Dermatol 2011;28:519-23.

58. Avril M, Riley C. Management of epidermolytic ichthyosis in the newborn. Neonatal Netw 2016;35:19-28.

59. Kubo Y, Urano Y, Matsuda, R. Ichthyosis Hystrix, Curth-Macklin Type: A New Sporadic Case With a Novel Mutation of Keratin 1 Arch Dermatol 2011;147(8):999-1001. doi:10.1001/archdermatol.2011.217

60. Cervantes T, Pham C, Browning JC. Superficial epidermolytic ichthyosis: a report of two families Pedietr Dermatol 2013;30(4):469-72. doi: 10.1111/j.1525-1470.2012.01750

61. Guerra L, Diociaiuti A, El Hachem M, Castiglia D, Zambruno G. Ichthyosis with confetti: clinics, molecular genetics and management. Orphanet J Rare Dis 2015;10:115. doi: 10.1186/s13023-0150336-4.

62. Suzuki S, Nomura T, Miyauchi T, Takeda M. Revertant Mosaicism in Ichthyosis with Confetti Caused by a Frameshift Mutation in KRT1. J Investig Dermatol Symp Proc 2016;136(10):2093-95. doi: 10.1016/j. jid.2016.05.109

63. Poulton, C, Gration, D. Autosomal recessive congenital ichthyosis due to homozygous variants in NIPAL4 with a dramatic response to ustekinumab. Pediatr Dermatol 2019;36(6):1002-3. doi: 10.1111/ pde.13995

64. Paller A, Mancini A. Hurwitz Clinical Pediatric Dermatology 4 th Revised edition - A Textbook of Skin Disorders of Childhood and Adolescence, published Sep 2011, ISBN 1437704123 